\title{
Immunodeficiencies with hypergammaglobulinemia: a review
}

\author{
Julia Upton*
}

\begin{abstract}
Primary immunodeficiencies (PID) can present with recurrent infections, autoimmunity, inflammation, or malignancy and each of these conditions can be associated with elevated immunoglobulin. A high level of immunoglobulin $\mathrm{G}(\mathrm{IgG})$ is an uncommon finding, especially in pediatrics, and does not rule out primary immunodeficiency. Deficiencies in varied aspects of immune response have been described with high IgG. Reported PID conditions with elevated IgG include defects in humoral, cellular, and innate immunity. Some of these immunodeficiencies can have fatal outcomes, some require hematopoetic stem cell transplantation, and some require systemic medications. The mechanisms driving elevated lgG are not well understood, but in some cases abnormal cytokine production has been proposed. The evaluation of a patient with high IgG is guided by the patient's history and a physical examination, with special attention to autoimmunity in pediatrics and malignancy and liver disease in adults. In the setting of autoimmunity, chronic gastrointestinal disease, or chronic infections, the measurement of specific antibodies to evaluate the function of the lgG should be considered. An increased appreciation of elevation in IgG reflecting immune dysregulation may lead to earlier PID diagnoses.
\end{abstract}

\section{Introduction}

In the course of a work-up for symptoms such as recurrent fevers and infections or concern about autoimmunity, the patient's level of $\operatorname{IgG}$ is often tested. Multiple papers and guidelines exist to assist the clinician with the immunodeficiency differential diagnosis for hypogammaglobulinemia, but high serum IgG has not been characterized in detail.

\section{Differential diagnosis of high IgG}

One of the largest retrospective series of mostly adult patients (aged 15-80 years) with elevated immunoglobulin (Dispenzieri et al. 2001) discovered that patients with high IgG fall into 1 of 5 major categories: liver disease, connective tissue diseases, chronic infections, hematologic disorders, and nonhematologic malignancies. No patients with immunodeficiency were described in this series or in the tables describing a wide variety of conditions with high IgG. Interestingly, 1 patient without a diagnosis did have poorly defined inflammatory lung disease with bronchiectasis and idiopathic pulmonary fibrosis, raising the possibility of immunodeficiency.

In the pediatric population, a recent retrospective study described the diagnoses of patients with $\operatorname{IgG}$ over $20 \mathrm{~g} / \mathrm{L}$ (Lo et al. 2013). In this study, high IgG was associated with autoimmune disorders, especially lupus and arthritis, as well as infectious etiology, malignancy or stem cell transplantation, immunodeficiency, medications, and other conditions such as portal hypertension. The rarity of the finding of hypergammaglobulinemia in children was stressed by Lo et al.
Division of Clinical Immunology and Allergy, Department of Pediatrics, Hospital for Sick Children, University of Toronto, Toronto, ON, Canada

*Corresponding author: Julia Upton/Julia.upton@sickkids.ca
Submitted 12 December 2014

Accepted 17 December 2014

Available online 18 December 2014

LymphoSign Journal 2:57-73 (2015)

dx.doi.org/10.14785/lpsn-2014-0019 
(2013) because during a decade at a tertiary children's hospital, only 442 patients were identified with high IgG. However, given their methodology, patients who were on intravenous immunoglobulin (IVIG) were understandably excluded. Therefore, the patients with diagnosed immunodeficiencies requiring immunoglobulin replacement were not included in this number. Only 15 of 442 patients had a recognized immunodeficiency. The captured immunodeficiencies with high IgG were varied and included hyper-IgE syndrome, ataxia-telangectasia, and autoimmune lymphoproliferative disease.

\section{Primary immunodeficiencies with high immunoglobulins could be missed}

Despite an effort to classify primary immunodeficiencies (PID) (Geha et al. 2007; Notarangelo et al. 2009), multiple recent publications have brought attention to the fact that PID with the same genetic mutation can have very variable presentations (Al-Herz and Notarangelo 2012; Maggina and Gennery 2013). It is already recognized that normal numbers of lymphocytes do not rule out immunodeficiency. For example, severe combined immunodeficiency (SCID) can present with a normal or elevated lymphocyte count due to either oligoclonal proliferation of T cells as seen in Omenn's syndrome (Villa et al. 2008) or expansion of the B-cell numbers in conditions such as JAK3 or IL-2 receptor gamma deficiency. Just as normal or elevated numbers of lymphocytes do not rule out immunodeficiency, the finding of elevated immunoglobulin may not be reassuring as to immune status. A long diagnostic delay for patients with common variable immunodeficiency has been recognized (Wood et al. 2007) and it is reasonable to assume that high immunoglobulins would delay diagnosis of an immunodeficiency even further.

Some immunodeficiencies are very well described as having high levels of immunoglobulins. For some conditions, the high immunoglobulin level is extremely informative as to the nature of the immunodeficiency. A collection of disorders have hyper-IgM as a result of the impaired ability of the B cell to switch immunoglobulin class (Ochs 2008). High IgE is a characteristic finding in hyper-IgE syndrome (Freeman and Holland 2009). Elevations in IgM and IgE are components of immunodeficiencies that are recognizable by that characteristic and will not be the focus of this review.

In contrast, hyper-IgG does not have a specific phenotype or allude to a specific diagnosis, but it includes very significant immunodeficiencies. This review aims to present the wide range of immunodeficiencies associated with hypergammaglobulinemia, including SCID, to illustrate that it is a described feature of many immunodeficiencies and to increase the recognition that the function of the IgG is more critical than the level.

\section{An illustrative case}

A 20-year-old male visited his primary care doctor because of recurrent sinus infections and 2 pneumonia diagnoses in the preceding year. His physical exam results were normal. Laboratory studies showed a normal blood count, and analysis of the immunoglobulins, performed to rule out hypogammaglobulinemia, showed elevated IgG. A serum protein electrophoresis that excluded monoclonality was performed. The evaluation was considered normal and immunodeficiency was considered to be ruled out. The elevated IgG was ascribed to the recurrent sinus infections.

Years later, a severe pneumonia prompted a referral to the Immunology Department. The Immunologist checked the function of the immunoglobulins by examining antibody titres. Specific antibody titres showed no response to protein and polysaccharide vaccinations despite an up-to-date schedule. By this point, a CT scan of the chest scan revealed bronchiectasis. A diagnosis of antibody deficiency with normal or elevated immunoglobulins (or dysgammglobulinemia) was made and the patient was started on intravenous gammaglobulin.

\section{Immunglobulin G}

Immunoglobulins are proteins composed of heavy chains and light chains. Their class is defined by the constant region of the heavy chain. IgG is the most abundant immunoglobulin and therefore constitutes most of the gamma region in serum protein electrophoresis. For the purposes of this review, hypergammaglobulinemia will focus on high IgG.

IgG is produced by B lymphoctytes. A naïve B cell can produce $\mathrm{IgD}$ and $\mathrm{IgM}$, but help is required to produce IgG cognate $\mathrm{T}$ lymphocyte. The $\mathrm{B}$ cell must receive the appropriate signals from the $\mathrm{T}$ lymphocyte to make an irreversible change in its DNA to undergo class switching to produce IgG. Without these signals, or without $\mathrm{T}$ lymphocytes, IgG cannot be produced.

IgG has important roles in immunity including complement activation and opsonization. The function of 
IgG differs by subclass. IgG is classified into 4 subclasses. IgG1 is the most abundant subclass and makes up about two-thirds of the total IgG. IgG1 and IgG3 can recognize protein and viral antigens. IgG2 recognizes polysaccharide antigens. The function of IgG4 is less elucidated (Aalberse et al. 2009). IgG4 does not fix complement, and it increases in allergen immunotherapy and parasitic infections. The levels of IgG are age dependent (Schauer et al. 2003), so appropriate reference ranges should be used.

\section{Immunodeficiencies with high IgG}

A list of immunodeficiency conditions reported with hypergammaglobulinemia is presented in Table 1 . This table highlights a wide range of immunodeficiencies,

Table 1: A primary immunodeficiency conditions described with elevated IgG.

\begin{tabular}{|c|c|}
\hline Immunodeficiency & Major mechanism of immunodeficiency \\
\hline \multicolumn{2}{|l|}{ Predominantly humoral immunodeficiencies } \\
\hline Dysgammaglobulinemia/specific antibody deficiency & B-cell function \\
\hline \multicolumn{2}{|l|}{ Congenital defects of phagocyte number, function, or both } \\
\hline Chronic granulomatous disease & Neutrophil oxidative burst deficiency \\
\hline Congenital neutropenia & Lack of neutrophils (multiple mechanisms) \\
\hline \multicolumn{2}{|l|}{ Combined immunodeficiencies } \\
\hline RAG1 (Recombinant activating gene 1) deficiency & T-cell receptor generation abnormality \\
\hline ZAP-70 deficiency & Intracellular signaling abnormality \\
\hline MST1 deficiency & T-cell survival/apoptosis/regulatory function \\
\hline LRBA (LPS-responsive beige-like anchor) deficiency & Possible endocytosis defect, vesicular trafficking defect \\
\hline CD27 deficiency & T-cell and B-cell memory impairment \\
\hline \multicolumn{2}{|l|}{ Immunodeficiencies with associated or syndromic features } \\
\hline Wiskott-Aldrige syndrome & Actin cytoskeleton abnormality \\
\hline Ataxia-telangectasia & DNA repair abnormality \\
\hline Autosomal dominant hyper IgE syndrome (STAT-3 deficiency) & Intracellular signaling abnormality \\
\hline Autosomal recessive hyper IgE syndrome (DOCK8 deficiency) & NK- and B-cell function \\
\hline Netherton's syndrome (SPINK5) & Unopposed serine protease activity \\
\hline STAT-5b deficiency & Intracellular signaling abnormality \\
\hline ORAI1 deficiency & Ca++ channel defect \\
\hline Cartilage-hair hypoplasia & $\begin{array}{l}\text { Disturbance of mitochondrial RNA processing and cell } \\
\text { cycle control }\end{array}$ \\
\hline \multicolumn{2}{|l|}{ Diseases of immune dysregulation } \\
\hline $\begin{array}{l}\text { APECED (autoimmune polyendocrinopathy with candidiasis and } \\
\text { ectodermal dysplasia) }\end{array}$ & Failure of central tolerance \\
\hline $\begin{array}{l}\text { IPEX (Immunodeficiency, polyendocrinopathy, and enteropathy) } \\
\text { syndrome }\end{array}$ & Dysfunction of T-regulatory cells \\
\hline CD25 deficiency & Altered signaling by IL-2 \\
\hline Autoimmune lymphoproliferative syndrome & Failure of apoptosis \\
\hline XIAP deficiency & Apoptosis defect \\
\hline Chediak-Higashi syndrome & Abnormal organellar protein trafficking \\
\hline \multicolumn{2}{|l|}{ Defects in innate immunity } \\
\hline NEMO (Nuclear factor-kappa B essential modulator) deficiency & Failure of NEMO-induced NF- $\mathrm{NB}$ activation \\
\hline IRAK-4 and MyD88 deficiency & Toll-like receptor and IL-1 signaling defect \\
\hline Mutations in STAT1 & Intracellular signaling abnormality \\
\hline IL-17RA deficiency & Cytokine receptor signaling abnormality \\
\hline \multicolumn{2}{|l|}{ Auto-inflammatory disorders } \\
\hline Hyper-IgD syndrome (MVK deficiency) & Disorder of cholesterol metabolism \\
\hline Blau syndrome & NOD2 overactivity \\
\hline Tumor necrosis factor receptor-associated periodic syndrome & Disorder of tumor necrosis factor regulation \\
\hline \multicolumn{2}{|l|}{ Complement deficiencies } \\
\hline C2 deficiency & $\begin{array}{l}\text { Disorder of opsonization and immune complex } \\
\text { management }\end{array}$ \\
\hline
\end{tabular}


including fatal immunodeficiencies, that can have high IgG. They have been mostly organized according to the newest update on the classification of PIDs from the international union of immunological societies expert committee for PID (Al-Herz et al. 2014) in which the only PIDs specifically listed to be associated with high IgG are mammalian sterile20-like kinase 1 (MST1), also known as serine threonine kinase 4 (STK4) deficiency and autoimmune lymphoproliferative syndrome (ALPS), although many are described as having normal immunoglobulin levels. It is important to also recognize that many more of these PID conditions have been reported with elevated IgG to increase their recognition.

\section{Hypergammaglobulinemia in congenital defects of phagocyte number or function or both}

Since the 1950s, there has been recognition that significant immunodeficiencies can occur in the setting of high IgG. Chronic granulomatous disease (CGD) was first described as a disorder in which recurrent infections occur in the setting of hypergammaglobulinemia. This description predated the more advanced testing we have today and was intended to differentiate CGD from Bruton's agammaglobulinemia (Holland 2013). In CGD there is impairment in NADPH oxidase function. The neutrophils cannot generate superoxide anions and are therefore incapable of creating reactive oxygen intermediates and mounting an appropriate oxidative burst. This impairment leads to a susceptibility to infections with catalase-positive organisms. The NADPH oxidase also contributes to the formation of neutrophil extracellular traps (NETS), extracellular fibres released from the neutrophils that can bind pathogens. These patients can present with recurrent abscesses, Aspergillus infections, candidal infections, and Crohn's disease-like gastrointestinal disease. CGD can be inherited in an $\mathrm{X}$-linked dominant or an autosomal recessive pattern. $\mathrm{X}$-linked patients have the youngest and most severe presentation and they have mutations in gp91phox, which is specific to the neutrophils. Autosomal dominant patients have mutations in one of the other 4 proteins which compose the NADPH oxidase, $\mathrm{p} 47^{\text {phox }}, \mathrm{p} 67^{\text {phox }}, \mathrm{p} 22^{\text {phox }}$, or rarely $\mathrm{p} 40^{\mathrm{phox}}$. The immune evaluation will typically be normal other than a low neutrophil oxidative burst test, so a high level of suspicion is needed for diagnosis.

Patients with congenital neutropenia have also been found to have high IgG (Lo et al. 2013). Congenital neutropenia can be caused by multiple different genetic defects including elastase mutations (Horwitz et al. 2013). These patients have no characteristic clinical features other than neutropenia and infections. Many conditions cause congenital neutropenia (Boztug and Klein 2013) and those that have been described with hypergammaglobulinemia elsewhere in this review include ALPS, Chediak-Higashi syndrome, and Cartilage-hair hypoplasia. Many causes of congenital neutropenia include specific physical characteristics or associated features that can assist in narrowing down the diagnostic possibilities.

\section{Hypergammaglobulinemia in predominantly antibody immunodeficiencies}

Humoral immunodeficiencies are typically associated with hypogammaglobulinemia. However, there are conditions in which the immunoglobulin levels are normal (or high), but they are incapable of mounting a robust specific antibody response against infections. The International PID classification uses the term "Specific antibody deficiency with normal Ig concentrations and normal numbers of B cells" (Al-Herz et al. 2014) to refer to individuals who have normal immunoglobulins but have recurrent infections and poor responses to vaccines. This terminology does not explicitly describe that some patients with this phenotype can have high, rather than normal, immunoglobulins. Antibody deficiency with normal or elevated immunologlobulins (Nagumo and Komiyama 2000) recognizes that the immunoglobulins can be high. Some clinical immunologists may also use the term "dysgammaglobulinemia" to refer to these patients. The presence of recurrent infections with high immunoglobulins, but with a poor specific antibody production, is a phenotypic description and represents a compilation of different genetic disorders that will likely be further elucidated in the coming years. Specific antibody deficiency, otherwise known as selective IgG deficiency (Orange et al. 2012), is another phenotypic condition in which immunoglobulin levels are normal, but there is a poor response to polysaccharide antigens. This description does not currently specify that the IgG can be high. These conditions can exist on their own or as part of a broader phenotype.

\section{Hypergammaglobulinemia in combined T-cell and B-cell immunodeficiencies}

A combined immunodeficiency is one in which there is both a T-lymphocyte and B-lymphocyte deficiency. 
Many different monogenic combined immunodeficiencies affecting different areas of immune system development have been reported to have elevated IgG. For example, defects in T-cell receptor development, intracellular signaling, regulatory $\mathrm{T}$-cell development, endocytosis, and DNA repair have all been found to cause combined immunodeficiencies as well as high IgG.

$\mathrm{T}$ cells recognize antigen through their $\mathrm{T}$-cell receptors. These receptors need to be created from rearranging genomic DNA. Recombinant activating gene (RAG) deficiency leads to an impaired ability to create T-cell receptors. Classically, patients with deficiencies in RAG present with Omenn's syndrome or SCID. However, patients with RAG1 deficiency can have a very variable phenotype. These patients can have prominent autoimmune features and present like patients with granulomatosis with polyangitis (Avila et al. 2010) or they can have multiple autoimmune cytopenias with IgG above the typical reference range for age (Henderson et al. 2013; Chen et al. 2014).

Lymphocytes need to transmit signals from their various cell surface receptors to the nucleus to respond to stimuli. Alterations in lymphocyte signal transduction therefore cause immunodeficiencies, including fatal immunodeficiencies. After the T-cell receptor has bound an antigen, ZAP-70 (Zeta-chain-associated protein kinase 70) is recruited to the CD3 zeta chain and plays a critical role in further downstream signaling. Mutations in ZAP-70 have been described in about 20 families and lead to a severe combined immunodeficiency syndrome characterized by recurrent candidal and viral infections as well as opportunistic infections like Pneumocystis jiroveci pneumonia (PJP). The immune profile reveals low numbers of CD8 cells, but they can have normal or elevated B cells and IgG with poor specific antibody production (Fischer et al. 2010). These patients require hematopoetic stem cell transplantation for survival.

A newly described immunodeficiency, MST1 deficiency (also known as STK4 deficiency), is characterized clinically by mild cardiac abnormalities and recurrent bacterial, candidal, and viral infections including Epstein-Barr virus (EBV) and human papillomavirus. They also have a predisposition to lymphoma and autoimmunity. Despite their hypergammaglobulinemia, they have poor B- and T-cell responses (Abdollahpour et al. 2012). MST1 appears to have a role in regulating regulatory $\mathrm{T}$ cells through expression of FOXP3 (Du et al. 2014) as well as regulating T-cell apoptosis and survival (Nehme et al. 2012).

Recently, mutations in LPS-responsive beige-like anchor (LRBA) have been described in patients with a variable phenotype of immune dysregulation including inflammatory bowel disease and cytopenias, immunodeficiency, or a combination of all of these features. They have been reported with low, normal, and high IgG, even with the same familial mutation (Alangari et al. 2012). The exact role of LRBA in the immune system remains to be elucidated but is thought to be involved in endocytosis.

CD27 is a cell marker for memory lymphocytes and is important for NK-cell and T-cell cytotoxicity. CD27 deficiency patients can have a widely variable phenotype within the same family. The patient in the index case initially had elevated immunoglobulins with EBV infection, he then became hypogammaglobulinemic over time and had a good result with IVIG replacement (van Montfrans et al. 2012). However, his brother died from EBV-related aplastic anemia. Overall, 10 patients have been reported and their clinical phenotype has varied from B memory cell impairment to severe problems such as chronic EBV infection or malignancy (Parvaneh et al. 2013).

\section{Hypergammaglobulinemia in well-defined syndromes with immunodeficiency}

Some immunodeficiencies have strongly associated phenotypic features such as associated neurological impairments, skeletal abnormalities, or other characteristics that can assist in the diagnosis.

Ataxia-telangestasia is an immunodeficiency due to a defect in DNA repair. These patients develop progressive cerebellar defects and have a marked predisposition to malignancy and autoimmunity. Their immune defect is variable and can include humoral immune defects. A large series of patients was described in NowakWegrzyn et al. (2004) and 13\% of the patients had high IgG.

Wiskott-Aldrich Syndrome (WAS) patients are well described as having elevated immunoglobulins, especially IgA and IgE, but also high IgG (Massaad et al. 2013). The WAS gene encodes for the WAS protein that transmits signals from the surface of the cell to the actin cytoskeleton. The absence of WAS protein leads to a severe multisystem disorder that includes 
thrombocytopenia with small platelets, eczema, recurrent infections, and a marked predisposition to develop autoimmunity and malignancy. Many of these patients require bone-marrow transplantation owing to the severity of this condition.

Patients with hyper-IgE syndrome have been described to have high IgG in addition to the more recognized high IgE. In a series of 60 patients, from France, with signal transducer and activator of transcription 3 (STAT-3) mutations from 47 kindred it was found that $27 \%$ had high IgG (Chandesris et al. 2012). This autosomal dominant form of hyper-IgE syndrome is caused by dominant negative mutations in the intracellular signaling molecule STAT-3 (Sowerwine et al. 2012). It is characterized by recurrent skin and lung infections, skeletal abnormalities such as a propensity to fractures, a high arched palate, and retained primary teeth. Hyper-IgE syndromes can also present with chronic mucocutaneous candidiasis. They have a syndrome of both inefficient infection clearance and disordered inflammation. Patients with STAT-3 mutations have laboratory findings that include increased IgE and eosinophilia and impaired intracellular signaling to a very wide variety of stimuli including the IL-6 pathway and a deficiency of IL-17A and IL-22 producing $\mathrm{T}$ cells as well as a deficiency of memory B cells (Chandesris et al. 2012). Some of these patients require IVIG replacement for their poor specific antibody production.

The autosomal recessive form of hyper-IgE syndrome is caused by mutations in the dedicator of cytokinesis 8 (DOCK8) (Engelhardt et al. 2009; Zhang et al. 2009). In the initial description of this condition, 6 of 11 patients had elevated IgG (Zhang et al. 2009). These patients do not have the characteristic skeletal abnormalities of autosomal dominant hyper-IgE syndrome. They have a rash similar to atopic dermatitis, atopy, recurrent sinopulmonary infections, fungal infections including chronic mucocutaneous candidiasis (CMCC), and markedly increased viral susceptibility. Severe Herpes simplex, human papilloma virus infections, and mollescum contagiosum have been described. These patients can develop malignancies related to cutaneous viral infection as well as lymphoid malignancies. Commonly, these patients have lymphopenia and eosinophilia and variable specific antibody production. Patients with DOCK8 deficiency are far more likely than patients with atopic dermatitis to have low $\mathrm{CD} 4+$, low $\mathrm{CD} 8+$, and low memory CD8+ cells (Janssen et al. 2014). DOCK8 has multiple functions in the immune system including effects on NK- and B-cell function (Nishikimi et al. 2013). Recently, an impaired ability to affinity switch immunoglobulin and make long-lived immunoglobulin responses to antigen has been demonstrated in mice with defects in this gene (Randall et al. 2009). Reduced TH-17 cells have also been described. The recognition of DOCK8 deficiency is essential because this condition can be cured with hematopoetic stem cell transplantation (Su et al. 2011).

Netherton's syndrome occurs owing to mutations in the gene SPINK5, expressed in epithelial tissue. This mutation alters the LEKT1 protein and allows for unopposed serine protease activity in the skin and results in a condition of severe congenital ichythosis and recurrent infections, especially staphylococcal and viral. As these children grow older they develop atopy. Their immune evaluations typically demonstrate low NK cells, normal or high IgG, and elevated IgE (Judge et al. 1994).

Children with mutations in ORAI1 (Feske et al. 2010) have a syndrome of hypotonia, ectodermal dysplasia, and an immunodeficiency resulting in recurrent severe infections including to opportunistic infections. Their symptoms arise owing to a defect in specialized $\mathrm{Ca}^{++}$ channel signaling, which has profound effects in the development of multiple systems. The children have been described to have normal lymphocyte numbers but poor activation and normal or elevated IgG.

Another monoallelic immunodeficiency with a recognizable phenotype has been described in patients with STAT-5b mutations. These patients have dysmorphisms, eczema, diarrhea, pneumonias, and severe herpes virus infections. Their failure to thrive is likely mutifactorial, but growth hormone signaling is significantly affected in this condition; therefore, these patients can be identified by low IGF-1, low IGFBP-3, and high prolactin. Their immune evaluation finds normal T-, B-, and NK-cell counts, and they usually have hypergammaglobulinemia and elevated CD45RO counts (Verbsky and Chatila 2013).

Mutations in the ribonuclease mitochondrial RNA processing endoribonuclease gene result in a disturbance of mitochondrial RNA processing and cell cycle control and cause a highly variable phenotype that can include a combined immunodeficiency as well as short-limbed dwarfism called Cartilage-hair hypoplasia. In a series of 12 patients, the clinical heterogeneity, even within kindred, was stressed and 1 patient was described to have IgG $(18.2 \mathrm{~g} / \mathrm{L})$ at the age of 2.2 years (Kavadas et al. 2008) 


\section{Hypergammaglobulinemia in diseases of immune dysregulation}

There is an ever growing appreciation that autoimmunity is a manifestation of PID. A detailed review of autoimmunity and PID is beyond the scope of this review and has been extensively reviewed recently (Goyal et al. 2009; Schuetz et al. 2010; CunninghamRundles 2011; Atkinson 2012; Torgerson 2012; Todoric et al. 2013). One of the described autoimmunity conditions associated with PID is autoimmune cytopenias, but many other affected organ systems have been described.

Autoimmune cytopenias are a commonly presenting sign of humoral immunodeficiency. As an example, common variable immunodeficiency (CVID) is well described as presenting with immune-mediated thrombocytopenia (Michel et al. 2004). Persistent or difficult to control autoimmune cytopenias should prompt consideration for PID. By definition, CVID does not have hypergammaglobulinemia, but other immunodeficiencies that have been described with elevated immunoglobulins can have autoimmune cytopenias. One example is DOCK8 deficiency (Zhang et al. 2009).

As a cause of autoimmune cytopenias, ALPS deserves special mention. Some patients with an ALPS-like phenotype of lymphoproliferation and hypergammaglobulinemia can have B-cell subsets similar to those in (CVID) (Rensing-Ehl et al. 2010). There is increasing recognition of an overlap of these 2 clinical presentations. Patients with ALPS typically have high IgG, and in fact it is 1 component of the revised criteria (Oliveira et al. 2010).

A mutation in the autoimmune regulatory element (AIRE) causes derangements in central T-cell tolerance (Gallo et al. 2013). When $T$ cells are maturing, they need to learn self from non-self. The AIRE gene regulates the expression of self-antigens in the thymus so that developing $\mathrm{T}$ cells have exposure to self-antigens and autoreactive $\mathrm{T}$ cells can be deleted. Without this gene, multiple autoimmunity conditions arise. The development of autoantibodies interfering with TH-17 signaling is thought to underlie the susceptibility to candida in this condition (Puel et al. 2010a). These patients characteristically develop autoimmune polyendocrinopathy with candidiasis and ectodermal dysplasia (APECED). Patients with this condition have been reported to have elevated IgG. A large study of Finnish patients described a subset of 13 patients with skin rashes and of those 5 patients had hypergammaglobulinemia ranging from $24-51 \mathrm{~g} / \mathrm{L}$ (Perheentupa 2006).

Mutations in genes essential for regulatory T-cell function can cause combined immunodeficiencies with a predisposition to marked autoimmunity. The CD25 and FOXP3 genes both encode for key proteins involved in T-regulatory cell function. Autosomal recessive CD25 deficiency was reported in humans in 1997 as a syndrome in which there is marked infiltration of $\mathrm{T}$ cells in the lung, liver, gut, soft tissue, and bone as well as viral, fungal, and bacterial infections. T-cell proliferation in vitro was abnormal but IgG levels were slightly increased (Sharfe et al. 1997). Mutations in FOXP3 on the X-chromosome result in a severe disruption of regulatory $\mathrm{T}$ cells and result in a syndrome of immunodysregulation, polyendocrinopathy, and enteropathy (IPEX). These patients often have hypergammaglobulinemia (Verbsky and Chatila 2013). Both of these conditions can be treated with hematopoietic stem cell transplantation.

The X-linked immunodeficiency XIAP deficiency causes a combined immunodeficiency in which the hallmark is susceptibility to the development of hemophaocytic lymphohistiocytosis upon exposure to EBV. In a recent report of a series of 30 patients, 1 patient was described with elevated IgG (Pachlopnik Schmid et al. 2011). The molecular defect in XIAP confers an increased susceptibility to apoptosis and it interferes with many immunological signaling pathways. Patients with XIAP deficiency are at risk of early death, so this is another very significant immunodeficiency in which the laboratory investigations can show elevated IgG.

Another immunodeficiency that has been described with hypergammaglobulinemia is Chediak-Higashi Syndrome (CHS). In a Venezuelan series, 3 out of 4 of the patients had elevated IgG (Merino et al. 1983). CHS is caused by mutations in LYST and results in abnormal organelle trafficking. These patients have a recognizable syndrome of disordered immunity in which they typically have partial occulocutaneous albinism and recurrent infections especially to Staphylococcus aureus, Streptococcus pyogenes, and Pneumococcus species. If they survive childhood they can develop significant neurological defects such as peripheral neuropathy. Many patients go on to an accelerated phase in which they develop hemophaocytic lymphohistiocytosis (Kaplan et al. 2008). Bone-marrow transplantation can cure the hematological and immunological aspects of 
this condition but not the neurological manifestations (Tardieu et al. 2005).

\section{Hypergammaglobulinemia in innate immune defects}

The innate immune system is so described because it consists of the first line of defense against infections without requiring prior exposure. The innate immune system recognizes preserved antigens in bacteria and viruses. Mutations in IRAK-4 affect signaling through multiple Toll-like receptors and interleukin 1 receptors (von Bernuth et al. 2012). Recently, mutations in IRAK-4 have also been demonstrated to impair T-cell activation, so there may be a larger role for IRAK-4 in adaptive immunity than currently recognized (McDonald et al. 2010). A mutation in IRAK-4 was reported to cause hypergammaglobulinemia (Ku et al. 2007) in a patient with recurrent invasive pneumococcal disease including an episode of meningitis. This patient had good vaccine responses to protein antigens but impaired responses to pneumococcal antigens and low titres to isohemagluttinins. In addition to an infectious history of severe noninvasive and invasive infections from Streptococcal pneumonia, Pseudomonas aeriginosa, and Staph aureus starting at a young age, patients with IRAK-4 deficiency tend to have a blunted inflammatory response to infections, such as the lack of a high fever in the setting of meningitis. In a large series of 48 patients with IRAK-4 deficiency, 12 patients were found to have high IgG (Picard et al. 2010).

The clinical phenotype of IRAK-4 deficiency is indistinguishable from the phenotype of another innate immune defect, MyD88 deficiency. MyD88 is upstream of IRAK-4 in the Toll-like receptor signalling pathway. Indeed, these patients can also have hypergammaglobulinemia: 4 of 12 patients with MyD88 deficiency had high IgG levels (Picard et al. 2010). This combined series of IRAK-4 and MyD88 deficient patients demonstrated the severity of these conditions with a mortality of $38 \%$.

Downstream of MyD88 and IRAK-4 is the nuclear factor-kappa B essential modulator (NEMO). Hypomorphic mutations in NEMO can cause high IgG. In a detailed report of 72 patients (Hanson et al. 2008), 9 patients were known to have high IgG and another was listed as having high IgG1 and IgG4, so he too likely had total elevated IgG. This series reported that 2 of 10 patients died in childhood. Children with NEMO mutations have a complex phenotype. Some, but not all children, have ectodermal dysplasia and they have variable immune defects. Additionally some children have a susceptibility to mycobacteria and they may have antibody deficiency or a hyper-IgM syndrome.

Some mutations in the transcription factor, STAT-1, alter signaling of cytokines including that of IFNgamma, IL-6, and IL-21 reduce IL-17 producing T cells and can cause CMCC, recurrent viral infections, enteropathy, mycobacterial infections, and multiple endocrine autoimmunity (Uzel et al. 2013). These patients can have elevated immunoglobulins with poor antibody production among other immune abnormalities such as lymphopenia. Importantly, high IgG is not reassuring at all in STAT1 mutations. A child with a heterozygous mutation in the DNA binding domain of STAT1 was reported to have high IgG, CMCC, and a combined, progressive immunodeficiency so profound that death occurred in childhood (Sharfe et al. 2014).

Another cause of CMCC causing hypergammaglobulinemia has been described. A mutation in IL-17RA was identified in a boy with C. albicans and S. aureus dermatitis born to consanguineous parents. This mutation caused deficiency of IL-17RA and completely abolished responses to IL-17A and IL-17F (Puel et al. 2011).

\section{Hypergammaglobulinemia in auto- inflammatory disorders}

Increasing understanding of the inflammasome and defects in its regulation has shed light on the autoinflammatory conditions. Autoinflammatory conditions include the classic periodic fever syndromes, as well as some newer conditions described such as DIRA (deficiency of the IL-1 receptor antagonist). Many autoinflammatory conditions have been reported to have hypergammaglobulinemia (Kastner et al. 2010). These conditions are well known to have high IgG and not classic primary immunodeficiencies, so they will not be discussed in detail. Tumor necrosis factor receptorassociated periodic syndrome (Cantarini et al. 2012), mutations in mevalonate kinase (Bader-Meunier et al. 2011), proteasome associated disorders (GoldbachMansky 2012), and Blau syndrome (Sfriso et al. 2012) have all been described with hypergammaglobulinemia.

Schnitzler syndrome is a considered an autoinflammatory syndrome with a constellation of recurrent fevers, urticarial-like rash, joint inflammation, hepatosplenomegaly, and lymphadenopathy. Although these 
patients typically have an elevated monoclonal IgM, there are IgG variants (Schuster et al. 2009).

\section{Hypergammaglobulinemia in complement deficiencies}

Complement is a collection of more than 40 proteins that have an important role in the innate immune system with a wide range of functions including opsonization and clearance of immune complexes (Mayilyan 2012). Patients with inherited deficiencies in complement can present with infections, autoimmunity, paroxysmal nocturnal hemoglobinuria, or uncontrolled swelling. Complement deficiency is well reported as associated with systemic lupus erythematosus (SLE) (Leffler et al. 2014). The first report of C2 deficiency with SLE and nephritis described significant hypergammaglobulinemia in this patient (Roberts et al. 1978), thus illustrating another category of immunodeficiencies that can have high IgG.

\section{Conditions that may represent a primary immunodeficiency}

Figure 1 summarizes broad conditions and presentations as discussed in this review that may be associated with both a primary immunodeficiency and hypergammaglobulinemia.

\section{Chronic infections}

Hypergammaglobulinemia is described in the setting of chronic infections (Dispenzieri et al. 2001; Lo et al. 2013). Chronic infections can of course be a major presentation of primary immunodeficiency. A few key

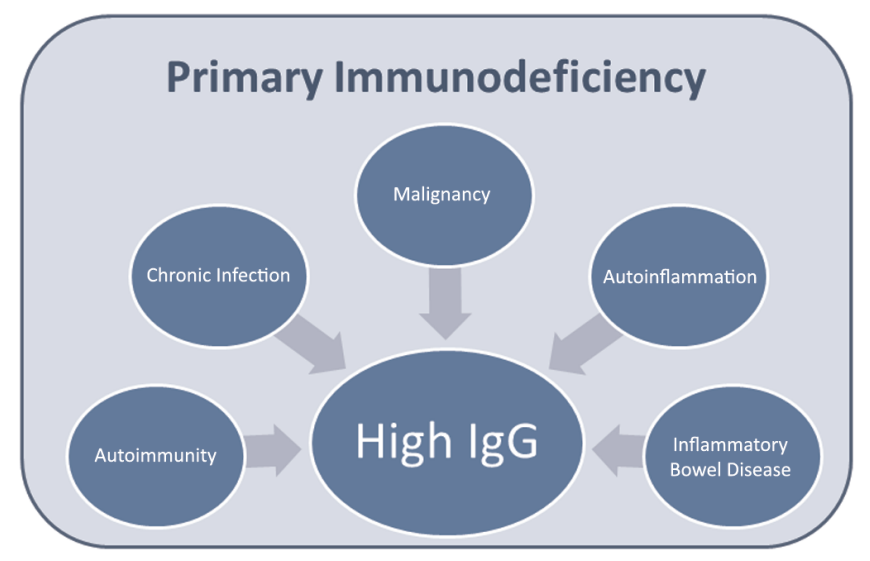

Figure 1: Many conditions associated with hypergammaglobulinemia may have an underlying, causative primary immunodeficiency. infections will be expanded upon that demonstrate the link between chronic infection and underlying immunodeficiencies.

As discussed in earlier sections, chronic mucocutaneous candidiasis, chronic sinopulmonary infections as seen in humoral immunodeficiencies and combined immunodeficiencies, abscesses as seen in neutrophil defects, and other severe, persistent, unusual and recurrent infections can be a hallmark of primary immunodeficiency.

EBV infections are described as causing hypergammaglobulinemia (Lo et al. 2013). As discussed above, a susceptibility to herpes viruses can be due to many immunodeficiencies. Many monogenic immunodeficiencies can lead to difficulty clearing EBV including ones mentioned earlier in this review such as STK4 deficiency, XIAP, CD27 deficiency, as well as others (Parvaneh et al. 2013).

\section{Inflammatory bowel disease}

Inflammatory bowel disease (IBD) is associated with hypergammaglobulinemia (Dispenzieri et al. 2001; Lo et al. 2013). Multiple monogenic diseases involving the immune system have now been discovered that can lead to immunodysregulation and the clinical presentation of colitis (Uhlig 2013). In this review, some of these genetic causes have been discussed as combined immunodeficiencies such as LRBA deficiency, IPEX syndrome, and CD25 deficiency. Clearly, IBD can be a manifestation of an immune system disorder, so attributing the hypergammaglobulinemia to the presence of IBD may miss that the IBD and the hypergammaglobulinemia are actually symptoms of an underlying primary immunodeficiency. Although the monogenic diseases causing IBD tend to present very young, some conditions associated with chronic inflammatory GI pathology and hypergammaglobulinemia such as autosomal recessive chronic granulomatous disease and dysgammaglobulinemia can present in adults.

\section{Malignant conditions}

It is recognized in both large series of hypergammaglobulinemia (Dispenzieri et al. 2001; Lo et al. 2013) that malignancy can cause elevated immunoglobulins. Many leukemias and lymphomas have been described with high IgG. A more detailed review of immunodeficiencies that predispose to malignancies can be found elsewhere (de Miranda et al. 2011; Leechawengwongs and Shearer 2012). Multiple myeloma (Fonseca and 
Monge 2013) is of course 1 of the characteristic conditions that can present with elevated immunoglobulins but will not be discussed in any detail in this review.

Many of the primary immunodeficiencies previously listed in this review are strongly associated with the development of lymphoma including ataxia-telangectasia (de Miranda et al. 2011), ALPS (Rao and Oliveira 2011), and STAT-3 deficiency (Leonard et al. 2004). The recognition of single gene defects in the immune system contributing to malignancy predisposition will no doubt be further developed in the future.

\section{Other conditions}

High IgG has been noted in some benign hematological conditions such as the histiocytic disease RosaiDorfman (Kutlubay et al. 2014) and idiopathic plasmacytic lymphadenopathy with polyclonal hypergammaglobulinemia (Kurosawa et al. 2009) and Castleman's disease (Hanada et al. 2012). Given that the underlying genetic etiology of these conditions is not understood and there is profound immune dysregulation, they have been included in this review as conditions possibly reflective of a primary immunodeficiency.

\section{Mechanisms of hypergammaglobulinemia}

This review has documented a very wide range of primary immunodeficiency conditions that can have hypergammaglobulinemia as a feature. The mechanisms underlying the development of high IgG in these conditions is varied. Overall the etiology of hypergammaglobulinemia is not well known. Some of the proposed mechanisms will be discussed.

High IgG appears to be a non-specific reactive inflammatory marker with variable correspondence to other inflammatory makers. For example, previous work in autoimmunity showed that patients with mixed connective tissue disease had the highest IgG but only slightly increased C-reactive protein (CRP), whereas rheumatoid arthritis patients had high CRP levels and slightly increased IgG levels, and patients with SLE showed high IgG levels and low CRP levels (Bakri Hassan et al. 1998).

Hypergammaglobulinemia can also be induced in murine models of autoimmunity. In a recent report, double transgenic mice were created in which the B cells expressed a specific lambda 2 light chain and the T cells expressed a cognate T-cell receptor. These idiotypespecific $\mathrm{T}$ cells were found to drive oligoclonal expansion of autoreactive B cells and within a few weeks many of the B cells produced antibodies specific for anti-ds DNA and hypergammaglobulinemia (Aas-Hanssen et al. 2014).

Chronic infections may be a cause of hypergammaglobulinemia. Murine studies have shown that viruses that lead to a persistent state can lead to hypergammaglobulinemia, whereas when viruses are cleared quickly they lead to only a transient increase in IgG. The development of hypergammaglobulinemia in this model relied on cognate $\mathrm{T}$-cell help, presumably for the $\mathrm{B}$ cell switch to IgG (Hunziker et al. 2003). Therefore, in PID, the inability to mount an effective immune response may be a cause of elevated IgG. Some infections, such as HIV, are chronic because they can evade even healthy immune systems. But in other chronic infections, consideration should be given to the host factors, such as PID, that lead to the inability to clear the infection. Certainly this chronic infection hypothesis is a likely reason for elevated IgG in patients who suffer from severe, persistent infections, but it may not be the only mechanism.

Aberrations in cytokine secretion may also contribute to hypergammaglobulinemia. Elevated IL-21, IFN- $\gamma$, IL6 , and IL-17 have been implicated in several syndromes associated with autoimmunity-related hypergammaglobulinemia (Sweet et al. 2012). Interestingly, many of the immunodeficiencies known to be associated with elevated IgG have defects affecting these pathways. For example, in STAT-3 deficient hyper-IgE syndrome, response to IL-6 and IL-10 is impaired, leading to a reduction in TH-17 responses as measured by production of IL-17 (Minegishi and Karasuyama 2009). Many of the immunodeficiencies listed in this review can present with CMCC, which is known to be associated with defects in TH-17 function (Puel et al. 2010b).

Abnormalities in cytokine production are also found in the autoinflammatory conditions. These syndromes have a marked elevation of IL-1 and often clinically respond to the IL-1 receptor blockade (Jesus and Goldbach-Mansky 2014); however, there is little information available about the response of the elevated IgG to IL-1 blockade. In Schnizler's syndrome, it has been reported that the clinical features responded to the IL-1 blockade, but the monoclonal protein (Schuster et al. 2009) did not, even after 8 months of treatment. 


\section{Suggested approach to evaluate for and treat PID in the setting of hypergammaglobulinemia}

Lo et al. (2007) suggested that in pediatrics about half of the patients found to have an IgG over $20 \mathrm{~g} / \mathrm{L}$ will have autoimmunity, and the likelihood of finding autoimmunity can be further improved by finding an elevated CRP, by being female, and by examining the hemoglobin and white blood cell count.

Detailed instructions of when to suspect PID are beyond the scope of this document. Warning signs of immunodeficiency (Jeffrey Model Foundation 2013) have been suggested to capture individuals suspected of immunodeficiency. These signs were evaluated recently and sensitivity and specificity were lower than ideal (Arkwright and Gennery 2011), partly because of the new understanding of what constitutes an immunodeficiency. The classic warning signs do not capture individuals with 1 very severe infection, chronic EBV, or with immune dysregulation such as that seen in early onset autoimmunity and inflammation. Screening criteria for PID will continue to evolve as the variability of existing immunodeficiencies and new immunodeficiencies are further recognized. Lists of warning signs specific to the pediatric population (Subbarayan et al. 2011) and specific to different specialists (CostaCarvalho et al. 2014) were recently published. Immunodeficiency Canada has suggested a list of red flags that includes features of immune-dysregulation such as infantile diarrhea as well as more classic signs of immunodeficiency (Immunodeficiency Canada 2014).

Clearly, the IgG should not be the only screen for the presence of immunodeficiency, but in someone in whom immunoglobulins were ordered due to clinical suspicion for their derangement, the goal of this review is to stress that elevated immunoglobulins still leave many viable and serious diagnostic possibilities. The function of the immune system can be screened by asking about signs and symptoms of immunodeficiency as well as examining the complete blood count and differential and the specific antibody production to vaccines and prior infections (Locke et al. 2014). Table 2 presents generalized information relevant to the work-up of high immunoglobulins based on the conditions described. Other authors have suggested that an immune evaluation for patients with conditions associated with PIDs, such as autoimmune cytopenias, should be performed (Michel et al. 2004) prior to the initiation of drugs
Table 2: Considerations for evaluation for immunodeficiency in the setting of hypergammaglobulinemia.

Full history and physical with special attention to the following

Key history points: consanguinity, family history of PID, severe/unusual/recurrent/persistent infections, early onset autoimmunity including cytopenias, easy fractures, granulomas, joint symptoms, fevers, B-symptoms, diarrhea

Key physical features: dysmorphism, ectodermal dysplasia, thrush, large or absent/small lymph nodes, splenomegaly, nail abnormalities, skin rashes, ataxia

Key screening labs: $\mathrm{Cbc}$ and differential, $\lg \mathrm{A}$, $\lg \mathrm{M}$, $\lg \mathrm{E}$; titres to vaccines/infections to assess immunoglobulin function; hemoglobin, wbc, CRP to screen for autoimmunity (Lo et al. 2013); liver tests; consider EBV, CMV, HIV; consider serum protein electrophoresis or immunofixation if clonality or malignancy suspected; consider oxidative burst testing (such as dihidrorhodamine assay) if chronic granulomatous disease suspected

Low threshold for more advanced investigations (specific titres before and after pneumococcal vaccination, lymphocyte immunophenotyping, mitogen and antigen stimulation), genetic investigations

that interfere with immune assessment, such as IVIG or immunosuppressants. Clear documentation of the inability to mount appropriate vaccine responses is helpful for both elucidating an underlying diagnosis and for gaining approvals for treatments such as IgG replacement therapy.

\section{Summary}

A high IgG is an uncommon finding, especially in pediatrics, and can be associated with autoimmunity, malignancy, chronic infections, inflammation, and PID, including conditions that can have fatal outcomes and those that require hematopoetic stem cell transplanation. Each of these conditions has great overlap and each can be caused by genetic abnormalities in the immune system. Defects in many aspects of the immune system including defects in neutrophils, adaptive immunity, innate immunity, and tolerance can lead to hypergammaglobulinemia. Chronic infection and abhorrent cytokine production have been proposed as mechanisms for elevated IgG.

Given the vast range of genetic disorders that can lead to hypergammaglobulinemia, it is likely that hypergammaglobulinemia can be a feature of almost any PID. Many of the immunodeficiency conditions listed here have had many patients described with high IgG. Immunologists routinely perform more detailed 
immune evaluations in referred patients, regardless of the IgG level. However, at the front lines of patient care there is likely less appreciation of the importance of the function of the immune system and more reliance on the numbers. An increased appreciation of elevation in IgG reflecting immune dysregulation and (or) immunodeficiency may lead to more extensive immune evaluations and earlier PID diagnoses. For example, expansion of the definition of specific antibody deficiency to explicitly include elevated IgG and the expansion of the descriptions of PIDs to include high IgG as a possible feature may prove beneficial for diagnostic awareness of immunodeficiencies.

\section{References}

Aalberse, R.C., Stapel, S.O., Schuurman, J., and Rispens, T. 2009. Immunoglobulin G4: an odd antibody. Clin. Exp. Allergy. 39(4):469-477. doi: 10.1111/j.13652222.2009.03207.x.

Aas-Hanssen, K., Funderud, A., Thompson, K.M., Bogen, B., and Munthe, L.A. 2014. Idiotype-specific Th cells support oligoclonal expansion of anti-dsDNA B cells in mice with lupus. J. Immunol. 193(6):26912698. doi: 10.4049/jimmunol.1400640.

Abdollahpour, H., Appaswamy, G., Kotlarz, D., Diestelhorst, J., Beier, R., Schäffer, A.A., Gertz, E.M., Schambach, A., Kreipe, H.H., Pfeifer, D., Engelhardt, K.R., Rezaei, N., Grimbacher, B., Lohrmann, S., Sherkat, R., and Klein, C. 2012. The phenotype of human STK4 deficiency. Blood. 119(15):3450-3457. doi: 10.1182/blood-2011-09-378158.

Alangari, A., Alsultan, A., Adly, N., Massaad, M.J., Kiani, I.S., Aljebreen, A., Raddaoui, E., Almomen, A.-K., Al-Muhsen, S., Geha, R.S., and Alkuraya, F.S. 2012. LPS-responsive beige-like anchor (LRBA) gene mutation in a family with inflammatory bowel disease and combined immunodeficiency. J. Allergy Clin. Immunol. 130(2):481-488.e2. doi: 10.1016/j.jaci.2012. 05.043 .

Al-Herz, W., Bousfiha, A., Casanova, J.-L., Chatila, T., Conley, M.E., Cunningham-Rundles, C., Etzioni, A., Franco, J.L., Gaspar, H.B., Holland, S.M., Klein, C., Nonoyama, S., Ochs, H.D., Oksenhendler, E., Picard, C., Puck, J.M., Sullivan, K., and Tang, M.L.K. 2014. Primary immunodeficiency diseases: an update on the classification from the international union of immunological societies expert committee for primary immunodeficiency. Front. Immunol. 5:162. doi: 10.3389/fimmu.2014.00162.

Al-Herz, W., and Notarangelo, L.D. 2012. Classification of primary immunodeficiency disorders: one-fits-all does not help anymore. Clin. Immunol. 144(1):2425. doi: 10.1016/j.clim.2012.05.003.

Arkwright, P.D., and Gennery, A.R. 2011. Ten warning signs of primary immunodeficiency: a new paradigm is needed for the 21st century. Ann. NY Acad. Sci. 1238:7-14. doi: 10.1111/j.1749-6632.2011.06206.x.

Atkinson, T.P. 2012. Immune deficiency and autoimmunity. Curr. Opin. Rheumatol. 24(5):515-521. doi: 10.1097/BOR.0b013e32835680c6.

Avila, E.M., Uzel, G., Hsu, A., Milner, J.D., Turner, M. L., Pittaluga, S., Freeman, A.F., and Holland, S.M. 2010. Highly variable clinical phenotypes of hypomorphic RAG1 mutations. Pediatrics. 126(5):e1248e1252. PMID: 20956421. doi: 10.1542/peds.20093171.

Bader-Meunier, B., Florkin, B., Sibilia, J., Acquaviva, C., Hachulla, E., Grateau, G., Richer, O., Farber, C.M., Fischbach, M., Hentgen, V., Jego, P., Laroche, C., Neven, B., Lequerré, T., Mathian, A., Pellier, I., Touitou, I., Rabier, D., Prieur, A.-M., Cuisset, L., and Quartier, P. 2011. Mevalonate kinase deficiency: a survey of 50 patients. Pediatrics. 128(1):e152-e159. PMID: 21708801. doi: 10.1542/peds.2010-3639.

Bakri Hassan, A., Rönnelid, J., Gunnarsson, I., Karlsson, G., Berg, L., and Lundberg, I. 1998. Increased serum levels of immunoglobulins, C-reactive protein, type 1 and type 2 cytokines in patients with mixed connective tissue disease. J. Autoimmun. 11(5):503-508. doi: 10.1006/jaut.1998.0236.

Boztug, K., and Klein, C. 2013. Genetics and pathophysiology of severe congenital neutropenia syndromes unrelated to neutrophil elastase. Hematol. Oncol. Clin. North Am. 27(1):43-60, vii. doi: 10.1016/j. hoc.2012.11.004.

Cantarini, L., Lucherini, O.M., Muscari, I., Frediani, B., Galeazzi, M., Brizi, M.G., Simonini, G., and Cimaz, R. 2012. Tumour necrosis factor receptor-associated periodic syndrome (TRAPS): state of the art and future perspectives. Autoimmun. Rev. 12(1):38-43. doi: 10.1016/j.autrev.2012.07.020.

Chandesris, M.-O., Melki, I., Natividad, A., Puel, A., Fieschi, C., Yun, L., Thumerelle, C., Oksenhendler, E., Boutboul, D., Thomas, C., Hoarau, C., Lebranchu, Y., Stephan, J.-L., Cazorla, C., Aladjidi, N., Micheau, M., Tron, F., Baruchel, A., Barlogis, V., Palenzuela, G., Mathey, C., Dominique, S., Body, G., Munzer, M., Fouyssac, F., Jaussaud, R., Bader-Meunier, B., Mahlaoui, N., Blanche, S., Debré, M., Le Bourgeois, M., Gandemer, V., Lambert, N., Grandin, V., Ndaga, S., Jacques, C., Harre, C., Forveille, M., Alyanakian, M.-A., Durandy, A., Bodemer, C., Suarez, F., Hermine, O., Lortholary, O., Casanova, J.-L., Fischer, A., 
and Picard, C. 2012. Autosomal dominant STAT3 deficiency and hyper-IgE syndrome: molecular, cellular, and clinical features from a French national survey. Medicine (Baltimore). 91(4):e1-e19. doi: 10.1097/MD.0b013e31825f95b9.

Chen, K., Wu, W., Mathew, D., Zhang, Y., Browne, S.K., Rosen, L.B., McManus, M.P., Pulsipher, M.A., Yandell, M., Bohnsack, J.F., Jorde, L.B., Notarangelo, L. D., and Walter, J.E. 2014. Autoimmunity due to RAG deficiency and estimated disease incidence in RAG1/2 mutations. J. Allergy Clin. Immunol. 133 (3):880-882.e10. doi: 10.1016/j.jaci.2013.11.038.

Costa-Carvalho, B.T., Grumach, A.S., Franco, J.L., Espinosa-Rosales, F.J., Leiva, L.E., King, A., Porras, O., Bezrodnik, L., Oleastro, M., Sorensen, R.U., and Condino-Neto, A. 2014. Attending to warning signs of primary immunodeficiency diseases across the range of clinical practice. J. Clin. Immunol. 34(1):10-22. doi: 10.1007/s10875-013-9954-6.

Cunningham-Rundles, C. 2011. Autoimmunity in primary immune deficiency: taking lessons from our patients. Clin. Exp. Immunol. 164:6-11. doi: 10.1111/j. 1365-2249.2011.04388.x.

De Miranda, N.F., Björkman, A., and Pan-Hammarström, Q. 2011. DNA repair: the link between primary immunodeficiency and cancer. Ann. NY Acad. Sci. 1246:50-63. doi: 10.1111/j.1749-6632. 2011.06322.x.

Dispenzieri, A., Gertz, M.A., Therneau, T.M., and Kyle, R.A. 2001. Retrospective cohort study of 148 patients with polyclonal gammopathy. Mayo Clin. Proc. 76 (5):476-487. doi: 10.4065/76.5.476.

Du, X., Shi, H., Li, J., Dong, Y., Liang, J., Ye, J., Kong, S., Zhang, S., Zhong, T., Yuan, Z., Xu, T., Zhuang, Y., Zheng, B., Geng, J.-G., and Tao, W. 2014. Mst1/ Mst2 regulate development and function of regulatory $\mathrm{T}$ cells through modulation of Foxo1/Foxo3 stability in autoimmune disease. J. Immunol. 192(4):15251535. doi: 10.4049/jimmunol.1301060.

Engelhardt, K.R., Mcghee, S., Winkler, S., Sassi, A., Woellner, C., Lopez-herrera, G., Chen, A., Kim, H.S., Lloret, M.G., Schulze, I., Ehl, S., Thiel, J., Pfeifer, D., Veelken, H., Niehues, T., Siepermann, K., Weinspach, S., Reisli, I., Keles, S., and Genel, F. 2009. Large deletions and point mutations involving DOCK8 in the autosomal recessive form of the hyper-IgE syndrome. J. Allergy Clin. Immunol. 124(6):1289-1302. doi: 10.1016/j.jaci.2009.10.038.Large.

Feske, S., Picard, C., and Fischer, A. 2010. Immunodeficiency due to mutations in ORAI1 and STIM1. Clin. Immunol. 135(2):169-182. doi: 10.1016/j.clim.2010. 01.011 .
Fischer, A., Picard, C., Chemin, K., Dogniaux, S., le Deist, F., and Hivroz, C. 2010. ZAP70: a master regulator of adaptive immunity. Semin. Immunopathol. 32 (2):107-116. doi: 10.1007/s00281-010-0196-x.

Fonseca, R., and Monge, J. 2013. Myeloma: classification and risk assessment. Semin. Oncol. 40(5):554-566. doi: 10.1053/j.seminoncol.2013.07.002.

Freeman, A.F., and Holland, S.M. 2009. Clinical manifestations, etiology, and pathogenesis of the hyperIgE syndromes. Pediatr. Res. 65(5 Pt 2):32R-37R. doi: 10.1203/PDR.0b013e31819dc8c5.

Gallo, V., Giardino, G., Capalbo, D., Palamaro, L., Romano, R., Santamaria, F., Maio, F., Salerno, M., Vajro, P., and Pignata, C. 2013. Alterations of the autoimmune regulator transcription factor and failure of central tolerance: APECED as a model. Expert Rev. Clin. Immunol. 9(1):43-51. doi: 10.1586/eci.12.88.

Geha, R.S., Notarangelo, L.D., Casanova, J.-L., Chapel, H., Conley, M.E., Fischer, A., Hammarström, L., Nonoyama, S., Ochs, H.D., Puck, J.M., Roifman, C., Seger, R., and Wedgwood, J. 2007. Primary immunodeficiency diseases: an update from the International Union of Immunological Societies Primary Immunodeficiency Diseases Classification Committee. J. Allergy Clin. Immunol. 120(4):776-794. doi: 10.1016/j.jaci. 2007.08.053.

Goldbach-Mansky, R. 2012. Immunology in clinic review series; focus on autoinflammatory diseases: update on monogenic autoinflammatory diseases: the role of interleukin (IL)-1 and an emerging role for cytokines beyond IL-1. Clin. Exp. Immunol. 167 (3):391-404. doi: 10.1111/j.1365-2249.2011.04533.x.

Goyal, R., Bulua, A.C., Nikolov, N.P., Schwartzberg, P. L., and Siegel, R.M. 2009. Rheumatologic and autoimmune manifestations of primary immunodeficiency disorders. Curr. Opin. Rheumatol. 21(1):78-84. doi: 10.1097/BOR.0b013e32831cb939.

Hanada, T., Okuno, K., Okada, S., Fujimoto, M., Kuranobu, H., Hashida, Y., Ueyama, J., Murakami, J., Hayashi, A., Hanaki, K., and Kanzaki, S. 2012. Castleman disease in a child with short stature. Pediatr. Int. 54(5):720-724. doi: 10.1111/j.1442-200X.2012. 03589.x.

Hanson, E.P., Monaco-Shawver, L., Solt, L.A., Madge, L.A., Banerjee, P.P., May, M.J., and Orange, J.S. 2008. Hypomorphic nuclear factor-kappaB essential modulator mutation database and reconstitution system identifies phenotypic and immunologic diversity. J. Allergy Clin. Immunol. 122(6):1169-1177.e16. doi: 10.1016/j.jaci.2008.08.018.

Henderson, L.A., Frugoni, F., Hopkins, G., de Boer, H., Pai, S.-Y., Lee, Y.N., Walter, J.E., Hazen, M.M., and 
Notarangelo, L.D. 2013. Expanding the spectrum of recombination-activating gene 1 deficiency: a family with early-onset autoimmunity. J. Allergy Clin. Immunol. 132(4):969-971.e1-2. doi: 10.1016/j. jaci.2013.06.032.

Holland, S.M. 2013. Chronic granulomatous disease. Hematol. Oncol. Clin. North Am. 27(1):89-99, viii. doi: 10.1016/j.hoc.2012.11.002.

Horwitz, M.S., Corey, S.J., Grimes, H.L., and Tidwell, T. 2013. ELANE mutations in cyclic and severe congenital neutropenia: genetics and pathophysiology. Hematol. Oncol. Clin. North Am. 27(1):19-41, vii. doi: 10.1016/j.hoc.2012.10.004.

Hunziker, L., Recher, M., Macpherson, A. J., Ciurea, A., Freigang, S., Hengartner, H., and Zinkernagel, R.M. 2003. Hypergammaglobulinemia and autoantibody induction mechanisms in viral infections. Nat. Immunol. 4(4):343-349. doi: 10.1038/ni911.

Immunodeficiency Canada. 2014. Red Flags for Primary Immunodeficiency. Retrieved September 21, 2014, from http://immunodeficiency.ca/primary-immunodeficiency/warning-signs/.

Janssen, E., Tsitsikov, E., Al-Herz, W., Lefranc, G., Megarbane, A., Dasouki, M., Bonilla, F.A., Chatila, T., Schneider, L., and Geha, R.S. 2014. Flow cytometry biomarkers distinguish DOCK8 deficiency from severe atopic dermatitis. Clin. Immunol. 150(2):220 224. doi: 10.1016/j.clim.2013.12.006.

Jeffrey Model Foundation. 2013. 10 Warning Signs. Retrieved July 17, 2014, from http://www.info4pi. org/library/educational-materials/10-warning-signs.

Jesus, A. A., and Goldbach-Mansky, R. 2014. IL-1 blockade in autoinflammatory syndromes. Annu. Rev. Med. 65:223-244. doi: 10.1146/annurev-med061512-150641.

Judge, M.R., Morgan, G., and Harper, J.I. 1994. A clinical and immunological study of Netherton's syndrome. Br. J. Dermatol. 131(5):615-621. Retrieved from http://www.ncbi.nlm.nih.gov/pubmed/7999590.

Kaplan, J., De Domenico, I., and Ward, D.M. 2008. Chediak-Higashi syndrome. Curr. Opin. Hematol. 15 (1):22-29. doi: 10.1097/MOH.0b013e3282f2bcce.

Kastner, D.L., Aksentijevich, I., and Goldbach-Mansky, R. 2010. Autoinflammatory disease reloaded: a clinical perspective. Cell. 140(6):784-790. doi: 10.1016/j. cell.2010.03.002.

Kavadas, F.D., Giliani, S., Gu, Y., Mazzolari, E., Bates, A., Pegoiani, E., Roifman, C.M., and Notarangelo, L. D. 2008. Variability of clinical and laboratory features among patients with ribonuclease mitochondrial RNA processing endoribonuclease gene mutations. J. Allergy Clin. Immunol. 122(6):1178-1184. doi: 10.1016/j.jaci. 2008.07.036.
Ku, C.-L., von Bernuth, H., Picard, C., Zhang, S.-Y., Chang, H.-H., Yang, K., Chrabieh, M., Issekutz, A.C., Cunningham, C.K., Gallin, J., Holland, S.M., Roifman, C., Ehl, S., Smart, J., Tang, M., Barrat, F.J., Levy, O., McDonald, D., Day-Good, N.K., Miller, R., Takada, H., Hara, T., Al-Hajjar, S., Al-Ghonaium, A., Speert, D., Sanlaville, D., Li, X., Geissmann, F., Vivier, E., Maródi, L., Garty, B.-Z., Chapel, H., Rodriguez-Gallego, C., Bossuyt, X., Abel, L., Puel, A., and Casanova, J.-L. 2007. Selective predisposition to bacterial infections in IRAK-4-deficient children: IRAK-4-dependent TLRs are otherwise redundant in protective immunity. J. Exp. Med. 204(10):2407-2422. doi: 10.1084/jem.20070628.

Kurosawa, S., Akiyama, N., Ohwada, A., Warabi, M., Suenaga, M., Kojima, M., and Tomiyama, J. 2009. Idiopathic plasmacytic lymphadenopathy with polyclonal hypergammaglobulinemia accompanied with cutaneous involvement and renal dysfunction. Jpn. J. Clin. Oncol. 39(10):682-685. doi: 10.1093/jjco/ hyp073.

Kutlubay, Z., Bairamov, O., Sevim, A., Demirkesen, C., and Mat, M.C. 2014. Rosai-Dorfman disease: a case report with nodal and cutaneous involvement and review of the literature. Am. J. Dermatopathol. 36 (4):353-357. doi: 10.1097/DAD.0b013e31829e5564.

Leechawengwongs, E., and Shearer, W.T. 2012. Lymphoma complicating primary immunodeficiency syndromes. Curr. Opin. Hematol. 19(4):305-312. doi: 10.1097/MOH.0b013e328353fa13.

Leffler, J., Bengtsson, A.A., and Blom, A.M. 2014. The complement system in systemic lupus erythematosus: an update. Ann. Rheum. Dis. 73(9):1601-1606. doi: 10.1136/annrheumdis-2014-205287.

Leonard, G.D., Posadas, E., Herrmann, P.C., Anderson, V.L., Jaffe, E.S., Holland, S.M., and Wilson, W.H. 2004. Non-Hodgkin's lymphoma in Job's syndrome: a case report and literature review. Leuk. Lymphoma. 45(12):2521-2525. doi: 10.1080/10428190400004463.

Lo, M.S., Zurakowski, D., Son, M.B.F., and Sundel, R.P. 2013. Hypergammaglobulinemia in the pediatric population as a marker for underlying autoimmune disease: a retrospective cohort study. Pediatr. Rheumatol. Online J. 11(1):42. doi: 10.1186/1546-009611-42.

Locke, B.A., Dasu, T., and Verbsky, J.W. 2014. Laboratory diagnosis of primary immunodeficiencies. Clin. Rev. Allergy Immunol. 46(2):154-168. doi: 10.1007/ s12016-014-8412-4.

Maggina, P., and Gennery, A.R. 2013. Classification of primary immunodeficiencies: need for a revised 
approach?. J. Allergy Clin. Immunol. 131(2):292-294. doi: 10.1016/j.jaci.2012.10.008.

Massaad, M.J., Ramesh, N., and Geha, R.S. 2013. Wiskott-Aldrich syndrome: a comprehensive review. Ann. NY Acad. Sci. 1285:26-43. doi: 10.1111/nyas. 12049.

Mayilyan, K.R. 2012. Complement genetics, deficiencies, and disease associations. Prot. Cell. 3(7):487496. doi: 10.1007/s13238-012-2924-6.

McDonald, D.R., Goldman, F., Gomez-Duarte, O.D., Issekutz, A.C., Kumararatne, D.S., Doffinger, R., and Geha, R.S. 2010. Impaired T-cell receptor activation in IL-1 receptor-associated kinase-4-deficient patients. J. Allergy Clin. Immunol. 126(2):332-337. e1-2. doi: 10.1016/j.jaci.2010.05.013.

Merino, F., Klein, G.O., Henle, W., Ramirez-Duque, P., Forsgren, M., and Amesty, C. 1983. Elevated antibody titers to Epstein-Barr virus and low natural killer cell activity in patients with Chediak-Higashi syndrome. Clin. Immunol. Immunopathol. 27(3):326-339. doi: 10.1016/0090-1229(83)90085-5.

Michel, M., Chanet, V., Galicier, L., Ruivard, M., Levy, Y., Hermine, O., Oksenhendler, E., Schaeffer, A., Bierling, P., and Godeau, B. 2004. Autoimmune thrombocytopenic purpura and common variable immunodeficiency: analysis of 21 cases and review of the literature. Medicine (Baltimore). 83(4):254-263. Retrieved from http://www.ncbi.nlm.nih.gov/pubmed/ 15232313.

Minegishi, Y., and Karasuyama, H. 2009. Defects in JakSTAT-mediated cytokine signals cause hyper-IgE syndrome: lessons from a primary immunodeficiency. Int. Immunol. 21(2):105-112. doi: 10.1093/intimm/ dxn134.

Nagumo, H., and Komiyama, A. 2000. [Antibody deficiency with normal(or elevated) immunoglobulins]. Ryoikibetsu Shokogun Shirizu. (32):66-68. Retrieved from http://www.ncbi.nlm.nih.gov/pubmed/1121 2825.

Nehme, N.T., Pachlopnik Schmid, J., Debeurme, F., André-Schmutz, I., Lim, A., Nitschke, P., RieuxLaucat, F., Lutz, P., Picard, C., Mahlaoui, N., Fischer, A., and de Saint Basile, G. 2012. MST1 mutations in autosomal recessive primary immunodeficiency characterized by defective naive T-cell survival. Blood. 119(15):3458-3468. doi: 10.1182/blood-201109-378364.

Nishikimi, A., Kukimoto-Niino, M., Yokoyama, S., and Fukui, Y. 2013. Immune regulatory functions of DOCK family proteins in health and disease. Exp. Cell Res. 319(15):2343-2349. doi: 10.1016/j.yexcr. 2013.07.024.
Notarangelo, L.D., Fischer, A., Geha, R.S., Casanova, J.L., Chapel, H., Conley, M.E., Cunningham-Rundles, C., Etzioni, A., Hammartröm, L., Nonoyama, S., Ochs, H.D., Puck, J., Roifman, C., Seger, R., and Wedgwood, J. 2009. Primary immunodeficiencies: 2009 update. J. Allergy Clin. Immunol. 124(6):11611178. doi: 10.1016/j.jaci.2009.10.013.

Nowak-Wegrzyn, A., Crawford, T.O., Winkelstein, J.A., Carson, K.A., and Lederman, H.M. 2004. Immunodeficiency and infections in ataxia-telangiectasia. J. Pediatr. 144(4):505-511. doi: 10.1016/j.jpeds. 2003.12.046.

Ochs, H.D. 2008. Patients with abnormal IgM levels: assessment, clinical interpretation, and treatment. Ann. Allergy. Asthma Immunol. 100(5):509-511. doi: 10.1016/S1081-1206(10)60479-6.

Oliveira, J.B., Bleesing, J.J., Dianzani, U., Fleisher, T.A., Jaffe, E.S., Lenardo, M.J., Rieux-laucat, F., Siegel, R. M., Su, H.C., Teachey, D.T., and Rao, V.K. 2010. Revised diagnostic criteria and classification for the autoimmune lymphoproliferative syndrome (ALPS): report from the 2009. NIH International Workshop. 116(14):35-40. doi: 10.1182/blood-201004-280347.The.

Orange, J.S., Ballow, M., Stiehm, E.R., Ballas, Z.K., Chinen, J., De La Morena, M., Kumararatne, D., Harville, T.O., Hesterberg, P., Koleilat, M., McGhee, S., Perez, E.E., Raasch, J., Scherzer, R., Schroeder, H., Seroogy, C., Huissoon, A., Sorensen, R.U., and Katial, R. 2012. Use and interpretation of diagnostic vaccination in primary immunodeficiency: a working group report of the Basic and Clinical Immunology Interest Section of the American Academy of Allergy, Asthma \& Immunology. J. Allergy Clin. Immunol. 130(3): S1-S24. doi: 10.1016/j.jaci.2012.07.002.

Pachlopnik Schmid, J., Canioni, D., Moshous, D., Touzot, F., Mahlaoui, N., Hauck, F., Kanegane, H., Lopez-Granados, E., Mejstrikova, E., Pellier, I., Galicier, L., Galambrun, C., Barlogis, V., Bordigoni, P., Fourmaintraux, A., Hamidou, M., Dabadie, A., Le Deist, F., Haerynck, F., Ouachée-Chardin, M., Rohrlich, P., Stephan, J.-L., Lenoir, C., Rigaud, S., Lambert, N., Milili, M., Schiff, C., Chapel, H., Picard, C., de Saint Basile, G., Blanche, S., Fischer, A., and Latour, S. 2011. Clinical similarities and differences of patients with X-linked lymphoproliferative syndrome type 1 (XLP-1/SAP deficiency) versus type 2 (XLP-2/XIAP deficiency). Blood. 117(5):1522-1529. doi: 10.1182/ blood-2010-07-298372.

Parvaneh, N., Filipovich, A.H., and Borkhardt, A. 2013. Primary immunodeficiencies predisposed to Epstein-Barr virus-driven haematological diseases. 
Br. J. Haematol. 162(5):573-586. doi: 10.1111/bjh. 12422.

Perheentupa, J. 2006. Autoimmune polyendocrinopathy-candidiasis-ectodermal dystrophy. J. Clin. Endocrinol. Metab. 91(8):2843-2850. doi: 10.1210/jc. 2005-2611.

Picard, C., von Bernuth, H., Ghandil, P., Chrabieh, M., Levy, O., Arkwright, P.D., McDonald, D., Geha, R.S., Takada, H., Krause, J.C., Creech, C.B., Ku, C.-L., Ehl, S., Maródi, L., Al-Muhsen, S., Al-Hajjar, S., Al-Ghonaium, A., Day-Good, N.K., Holland, S.M., Gallin, J. I., Chapel, H., Speert, D.P., Rodriguez-Gallego, C., Colino, E., Garty, B.-Z., Roifman, C., Hara, T., Yoshikawa, H., Nonoyama, S., Domachowske, J., Issekutz, A.C., Tang, M., Smart, J., Zitnik, S.E., Hoarau, C., Kumararatne, D.S., Thrasher, A.J., Davies, E.G., Bethune, C., Sirvent, N., de Ricaud, D., Camcioglu, Y., Vasconcelos, J., Guedes, M., Vitor, A.B., Rodrigo, C., Almazán, F., Méndez, M., Aróstegui, J.I., Alsina, L., Fortuny, C., Reichenbach, J., Verbsky, J.W., Bossuyt, X., Doffinger, R., Abel, L., Puel, A., and Casanova, J.-L. 2010. Clinical features and outcome of patients with IRAK-4 and MyD88 deficiency. Medicine (Baltimore). 89(6):403-425. doi: 10.1097/MD. 0b013e3181fd8ec3.

Puel, A., Cypowyj, S., Bustamante, J., Wright, J.F., Liu, L., Lim, H.K., Migaud, M., Israel, L., Chrabieh, M., Audry, M., Gumbleton, M., Toulon, A., Bodemer, C., El-Baghdadi, J., Whitters, M., Paradis, T., Brooks, J., Collins, M., Wolfman, N.M., Al-Muhsen, S., Galicchio, M., Abel, L., Picard, C., and Casanova, J.-L. 2011. Chronic mucocutaneous candidiasis in humans with inborn errors of interleukin-17 immunity. Science. 332(6025):65-68. doi: 10.1126/science.120 0439.

Puel, A., Döffinger, R., Natividad, A., Chrabieh, M., Barcenas-Morales, G., Picard, C., Cobat, A., OuachéeChardin, M., Toulon, A., Bustamante, J., Al-Muhsen, S., Al-Owain, M., Arkwright, P.D., Costigan, C., McConnell, V., Cant, A.J., Abinun, M., Polak, M., Bougnères, P.-F., Kumararatne, D., Marodi, L., Nahum, A., Roifman, C., Blanche, S., Fischer, A., Bodemer, C., Abel, L., Lilic, D., and Casanova, J.-L. 2010a. Autoantibodies against IL-17A, IL-17F, and IL-22 in patients with chronic mucocutaneous candidiasis and autoimmune polyendocrine syndrome type I. J. Exp. Med. 207(2):291-297. doi: 10.1084/ jem.20091983.

Puel, A., Picard, C., Cypowyj, S., Lilic, D., Abel, L., and Casanova, J.-L. 2010b. Inborn errors of mucocutaneous immunity to Candida albicans in humans: a role for IL-17 cytokines?. Curr. Opin. Immunol. 22 (4):467-474. doi: 10.1016/j.coi.2010.06.009.

Randall, K.L., Lambe, T., Johnson, A.L., Johnson, A., Treanor, B., Kucharska, E., Domaschenz, H., Whittle, B., Tze, L.E., Enders, A., Crockford, T.L., BouriezJones, T., Alston, D., Cyster, J.G., Lenardo, M.J., Mackay, F., Deenick, E.K., Tangye, S.G., Chan, T.D., Camidge, T., Brink, R., Vinuesa, C.G., Batista, F.D., Cornall, R.J., and Goodnow, C.C. 2009. Dock8 mutations cripple B cell immunological synapses, germinal centers and long-lived antibody production. Nat. Immunol. 10(12):1283-1291. doi: 10.1038/ni.1820.

Rao, V.K., and Oliveira, J.B. 2011. How I treat autoimmune lymphoproliferative syndrome. Blood. 118 (22):5741-5751. doi: 10.1182/blood-2011-07-325217. Rensing-Ehl, A., Warnatz, K., Fuchs, S., Schlesier, M., Salzer, U., Draeger, R., Bondzio, I., Joos, Y., Janda, A., Gomes, M., Abinun, M., Hambleton, S., Cant, A., Shackley, F., Flood, T., Waruiru, C., Beutel, K., Siepermann, K., Dueckers, G., Niehues, T., Wiesel, T., Schuster, V., Seidel, M.G., Minkov, M., Sirkiä, K., Kopp, M.V., Korhonen, M., Schwarz, K., Ehl, S., and Speckmann, C. 2010. Clinical and immunological overlap between autoimmune lymphoproliferative syndrome and common variable immunodeficiency. Clin. Immunol. 137(3):357-365. doi: 10.1016/j.clim. 2010.08.008.

Roberts, J.L., Schwartz, M.M., and Lewis, E.J. 1978. Hereditary C2 deficiency and systemic lupus erythematosus associated with severe glomerulonephritis. Clin. Exp. Immunol. 31(2):328-338. Retrieved from http://www.pubmedcentral.nih.gov/articlerender. fcgi? artid $=1541209 \&$ tool $=$ pmcentrez\&rendertype $=$ abstract.

Schauer, U., Stemberg, F., Rieger, C.H.L., Borte, M., Schubert, S., Riedel, F., Herz, U., Renz, H., Wick, M., Carr-Smith, H.D., Bradwell, A.R., and Herzog, W. 2003. IgG subclass concentrations in certified reference material 470 and reference values for children and adults determined with the binding site reagents. Clin. Chem. 49(11):1924-1929. Retrieved from http:// www.ncbi.nlm.nih.gov/pubmed/14578325.

Schuetz, C., Niehues, T., Friedrich, W., and Schwarz, K. 2010. Autoimmunity, autoinflammation and lymphoma in combined immunodeficiency (CID). Autoimmun. Rev. 9(7):477-482. doi: 10.1016/j.autrev. 2010.02.005.

Schuster, C., Kränke, B., Aberer, E., Arbab, E., Sturm, G., and Aberer, W. 2009. Schnitzler syndrome: response to anakinra in two cases and a review of the literature. Int. J. Dermatol. 48(11):1190-1194. doi: 10.1111/j.1365-4632.2009.04151.x. 
Sfriso, P., Caso, F., Tognon, S., Galozzi, P., Gava, A., and Punzi, L. 2012. Blau syndrome, clinical and genetic aspects. Autoimmun. Rev. 12(1):44-51. doi: 10.1016/ j.autrev.2012.07.028.

Sharfe, N., Dadi, H.K., Shahar, M., and Roifman, C.M. 1997. Human immune disorder arising from mutation of the chain of the interleukin-2 receptor. Proc. Natl. Acad. Sci. 94(7):3168-3171. doi: 10.1073/pnas. 94.7.3168.

Sharfe, N., Nahum, A., Newell, A., Dadi, H., Ngan, B., Pereira, S.L., Herbrick, J.-A., and Roifman, C.M. 2014. Fatal combined immunodeficiency associated with heterozygous mutation in STAT1. J. Allergy Clin. Immunol. 133(3):807-817. doi: 10.1016/j.jaci. 2013.09.032.

Sowerwine, K.J., Holland, S.M., and Freeman, A.F. 2012. Hyper-IgE syndrome update. Ann. NY Acad. Sci. 1250:25-32. doi: 10.1111/j.1749-6632. 2011.06387.x.

Su, H.C., Jing, H., and Zhang, Q. 2011. DOCK8 deficiency. Ann. NY Acad. Sci. 1246:26-33. doi: 10.1111/j.1749-6632.2011.06295.x.

Subbarayan, A., Colarusso, G., Hughes, S.M., Gennery, A.R., Slatter, M., Cant, A.J., and Arkwright, P.D. 2011. Clinical features that identify children with primary immunodeficiency diseases. Pediatrics. 127(5): 810-816. doi: 10.1542/peds.2010-3680.

Sweet, R.A., Lee, S.K., and Vinuesa, C.G. 2012. Developing connections amongst key cytokines and dysregulated germinal centers in autoimmunity. Curr. Opin. Immunol. 24(6):658-664. doi: 10.1016/j.coi.2012. 10.003 .

Tardieu, M., Lacroix, C., Basile, D. Saint, and Fischer, A. 2005. Brief report progressive neurologic dysfunctions 20 years after allogeneic bone marrow transplantation for Chediak-Higashi syndrome. Blood. 106(1):40-42. doi: 10.1182/blood-2005-01-0319.Reprints.

Todoric, K., Koontz, J.B., Mattox, D., and Tarrant, T.K. 2013. Autoimmunity in immunodeficiency. Curr. Allergy Asthma Rep. 13(4):361-370. doi: 10.1007/ s11882-013-0350-3.

Torgerson, T.R. 2012. Immunodeficiency diseases with rheumatic manifestations. Pediatr. Clin. North Am. 59(2):493-507. doi: 10.1016/j.pcl.2012.03.010.

Uhlig, H.H. 2013. Monogenic diseases associated with intestinal inflammation: implications for the understanding of inflammatory bowel disease. Gut. 62(12): 1795-1805. doi: 10.1136/gutjnl-2012-303956.
Uzel, G., Sampaio, E.P., Lawrence, M.G., Hsu, A.P., Hackett, M., Dorsey, M.J., Noel, R.J., Verbsky, J.W., Freeman, A.F., Janssen, E., Bonilla, F.A, Pechacek, J., Chandrasekaran, P., Browne, S.K., Agharahimi, A., Gharib, A.M., Mannurita, S.C., Yim, J.J., Gambineri, E., Torgerson, T., Tran, D.Q., Milner, J.D., and Holland, S.M. 2013. Dominant gain-of-function STAT1 mutations in FOXP3 wildtype immune dysregulation-polyendocrinopathyenteropathy-X-linked-like syndrome. J. Allergy Clin. Immunol. 131(6):1611-1623. doi: 10.1016/j.jaci.2012. 11.054 .

Van Montfrans, J.M., Hoepelman, A.I.M., Otto, S., van Gijn, M., van de Corput, L., de Weger, R.A., Monaco-Shawver, L., Banerjee, P.P., Sanders, E.A.M., Jol-van der Zijde, C.M., Betts, M.R., Orange, J.S., Bloem, A.C., and Tesselaar, K. 2012. CD27 deficiency is associated with combined immunodeficiency and persistent symptomatic EBV viremia. J. Allergy Clin. Immunol. 129(3):787-793.e6. doi: 10.1016/j.jaci. 2011.11.013.

Verbsky, J.W., and Chatila, T.A. 2013. Immune dysregulation, polyendocrinopathy, enteropathy, X-linked (IPEX) and IPEX-related disorders: an evolving web of heritable autoimmune diseases. Curr. Opin. Pediatr. 25(6):708-714. doi: 10.1097/MOP.000000000 0000029.

Villa, A., Notarangelo, L.D., and Roifman, C.M. 2008. Omenn syndrome: inflammation in leaky severe combined immunodeficiency. J. Allergy Clin. Immunol. 122(6):1082-1086. doi: 10.1016/j.jaci.2008.09.037.

Von Bernuth, H., Picard, C., Puel, A., and Casanova, J.L. 2012. Experimental and natural infections in MyD88- and IRAK-4-deficient mice and humans. Eur. J. Immunol. 42(12):3126-3135. doi: 10.1002/eji. 201242683.

Wood, P., Stanworth, S., Burton, J., Jones, A, Peckham, D.G., Green, T., Hyde, C., and Chapel, H. 2007. Recognition, clinical diagnosis and management of patients with primary antibody deficiencies: a systematic review. Clin. Exp. Immunol. 149(3):410-423. doi: 10.1111/j.1365-2249.2007.03432.x.

Zhang, Q., Davis, J.C., Lamborn, I.T., Freeman, A.F., Jing, H., Favreau, A.J., Matthews, H.F., Davis, J., Turner, M.L., Uzel, G., Holland, S.M., and Su, H.C. 2009. Combined immunodeficiency associated with DOCK8 mutations. N. Engl. J. Med. 361(21):20462055. doi: 10.1056/NEJMoa0905506. 